\title{
The Struggle with Disease Taxonomy in Han Kang's The Vegetarian
}

\author{
Jharna Choudhury \\ Ph.D. Scholar. Tezpur University, Assam, India. ORCID ID: oooo-0oo2-0916-373. \\ Email:jharnachoudhuryı23@gmail.com
}

\begin{abstract}
The root cause of the suffering of Yeong-hye denies all clear-cut medical nomenclatures in Han Kang's novel The Vegetarian. This paper discusses how heath institutions (in the context of the text) negate the aspects of cultural oppression, sexual trauma and power-play (referring to Michel Foucault) within the family structure while formulating a categorical taxonomy of a disease. In a constant struggle with anorexia, vegetal metamorphosis and parallel dream sequences, the cause-effect relationships in the illness of Yeonghye and her sister In-hye defers end-significations with plurality. Bringing in Susan Bordo, the hierarchy of gender in the control over food choices is discussed in the light of etiology of Yeong-hye's disease, its "whatness", and how medical institutions define her clinical condition.
\end{abstract}

Keywords: Disease, Taxonomy, Han Kang, Gender, Health Institution

\section{Introduction}

With the nature of problematic etiology and deferred taxonomy, Han Kang's novel The Vegetarian (2007) stands out as a fiction of disease and illness. The plotline is primarily woven around the mental health of Yeong-hye and the surreal aspect of her transfusion into a plant-body. The causes which provoke this quasi-metamorphosis initiate the discussion of the struggle in psychiatric taxonomy. Jarring bodily behaviors in spaces like home, workplace, hospitals, and the recurrent imposition of medical help makes Yeong-hye an interesting site of health discussion.

Han Kang formulates a complex narrative thread and a dialogic plot, where the internal lives of the characters are focal points. The book is divided into three major sections, 'The Vegetarian', 'The Mongolian Mark' and the 'Flaming Trees'. Each section has a point of view, a narration from a new narrator. Amidst the patriarchal bondages, domestic abuses, personal limitations and symbolic undertones, this book, in a post-structuralist way, defers the etiology (manner of causation of a disease, cause of abnormality/ unfamiliarity) of the struggle of Yeonghye's body. The essay "Etiology in a taxonomy of illnesses", puts forward the urgency of medical categorization of a disease, saying, "Once illnesses have been defined, a taxonomy of illnesses is the classification of illnesses resulting from this - so long as the defined illnesses/anomalies constitute a set of mutually exclusive and all-inclusive categories/taxa." (Steurer et al., 2006, p.88). A demarcation of mental illness, a clean taxa of a disease, which creates the situational horror in the book, is difficult to be made.

Han Kang's The Vegetarian reaches out to a larger audience, and in the hands of the translator Deborah Smith, the cultural and gendered oppression against Korean women, which later takes the form of a clinical condition, is very much evident in the narrative. The text (c) AesthetixMS 2020. This Open Access article is published under a Creative Commons Attribution Non-Commercial 4.o International License (http://creativecommons.org/licenses/by-nc/4.o/), which permits non-commercial re-use, distribution, and reproduction in any medium, provided the original work is properly cited. For citation use the DOI. For commercial re-use, please contact editor@rupkatha.com. 
constructs varied worlds, the first being the gendered world or the patriarchal world of Yeonghye's father, husband (Mr Cheong) and brother-in-law. There is an urgency in this world to completely mould and discipline Yeong-hye's body, once she transgresses the "standard" of the being an ideal woman. The second world is the struggle of Yeong-hye's self, her personality, with schizophrenia, anorexia, hallucination and body dysmorphia disorder. The third world is the dream world, the subconscious which creates the idea of an infectious disease, which Yeong-hye apparently spreads out to her sister In-hye. The three worlds are so conflicting in nature that there is a struggle for an etiology of Yeong-hye's disease, and hence a lag in taxonomy.

\section{Discipline, Disease and Gender Roles}

There are three causal objectifications of Yeong-hye's body in the text. Mr. Cheong, her husband introduces her character as an unremarkable woman, average, unattractive, with less sexual promiscuity, sickly skin and timid attitude. He engages the reader in continuously nullifying her body. The sight of her flat breast and her hypersensitivity in accentuating her breast with a padded bra stood as a mark of disapproval for Mr. Cheong. He undermined her as a wife, deemed her unimportant and unnoticeable until a sudden change ushered in her behaviour, that is when Yeong-hye developed an interest in vegetarianism. In the text, the non-consumption of meat extends beyond the implication of a dietary structure and mindfully explains Yeong hye's transgression, bodily revolution against the most important food item (meat) in Korean households. Her absent-being inside the house, was suddenly felt with a ghost-like presence. Mr. Cheong is aghast and remarks about her, "standing, motionless, in front of the fridge" (Han \& Smith, 2015, p. 7), and that "it was almost as if she were some ghost, silently standing its ground" (Han \& Smith, 2015, p. 7), clearing out the meat items. Her bodily stillness overpowers her need for sexual desire; she confuses human body-smell with the smell of meat to-be-consumed. With least consideration about her sexual troubles, she is victimized with marital rape. Clinically speaking, her condition would be termed as anorexia and bulimia; but the involvement of continuous traumatic oppressions (rape, food rules, standards of beauty and womanhood), both cultural and bodily, makes the taxonomy inadequate. Yeong-hye negotiates a life between the human world and the plant world, as an abject (Julia Kristeva's term), and is soon turned into an outcast, a medical body which needs attention. She acquired "the quiet tone of a person who didn't belong anywhere, someone who had passed into a border area between states of being" (Han \& Smith, 2015, p. 70-71). In the gender and power axis of Susan Bordo, as mentioned in the book Unbearable Weight (1993), she says, women faces the weight of constructive criticisms hidden under the garb of positivity by the male sexual counterparts, and the anorectic woman continuously suffers in the illusion of perfection.

Yeong hye's condition worsened when her corporeal obsession of vegetarianism infuriated her father, who forcefully shoved meat in her mouth. This is a significant episode which marks the beginning of metamorphosis with a symbolic fellatio with chopsticks (a phallic symbol). It also triggered her childhood trauma of eating meat of her pet dog that was killed by her father. Yeong-hye's anti-meat choice soon turned into a no-food obsession. Her internal suffering increased and she chose a process of self-cleansing. Won-Chung Kim's essay "Eating and Suffering in Han Kang's The Vegetarian" has something to say in this regard: "As anorexia is her endeavor to erase the trace of animal in her body, aphasia is then a process of purging the language contaminated with patriarchal ideology" (Kim, 2019, p. 8). Yeong-hye is determined to transpose into a body which needs no food and erases the need for a phallocentric language which is imbibed by the world of her father and husband. She eventually moves to pre-linguistic moans 
and groans to express her suffering; crossing the threshold of humanness, entering the world of animal kingdom and contemplating the need to morph into a plant body with sap fluids.

The third male member who abused her into a state of sheer speechlessness is her brother-in-law (unnamed in the book), who contrasted her body with the idea of imperfection that Mr. Cheong imposed on her. The former admired her for her free nature and very artistically wanted to capture her plant-like body through videography. The artistic bend of mind soon turns into the masculine sexual gaze, and Yeong-hye, in the decadence of her hospital accounts of mental illness, is entrapped. Susan Bordo would like to describe Yeong-hye's position as the weight of being reduced into the status of an "instinctual animals" (Bordo, 1993, p, 8). Yeong-hye's brother-in-law verbally described her situation as "post-suicide-attempt dementia" (Han \& Smith, 2015, p.69), a phase which indicates her "weak" PTSD state of mind; despite of which he acted as a predator over her body, his stature bringing a parallel story of mental dysfunction.

The linearity and organization of the medical institution which wants to cure the sudden anorexia of Yeong-hye overlooks the cultural dominations and the aspect of toxic masculinity in her life, of which she has been a forced consumer. These three men construct their own vocabulary of disease, a "mad woman" categorization for the dissent body of Yeong-hye, her food and dress choice. The etiology of the medical institution is sought by Yeong-hye's sister, who till the end wanted to know the reason behind the former's uncanny behaviors. Yeong-hye's body is "conventionally an object of desire, and yet it was a body from which all desire had been eliminated" (Han \& Smith, 2015, p. 85), "a body which said so much and yet was no more than itself" (Han \& Smith, 2015, p.87), all "armoured by the power of her own renunciation" (Han \& Smith, 2015, p.76). She was suddenly more inclined towards behaving as a plant body, being submerged in the vegetal world and retaining water and sunlight to survive. The medical institutions she has been admitted in were at loss, trying to demarcate the exact cause and locating the disease in her anatomy. As Foucault remarks, "Before it is removed from the density of the body, disease is given an organization, hierarchized into families, genera, and species." (Foucault \& Sheridan, 2003, p. 3). Yeong-hye suffers from being categorized into "this" and "that" kind of a diseased woman; and in the tug of war between the non-negotiating societal and medical worlds, she turns into an invalid.

Yeong-hye developed a vegetal thinking, a way of life where she not only controlled her food or her digestion, but also her body performances. She felt the need to acquire food like a plant, through the process of photosynthesis. The conversation:

"Yeong-hye cut her off. "They say my insides have all atrophied, you know." In-hye was lost for words. Yeong-hye moved her emaciated face closer to her sister. "I'm not an animal anymore, sister," she said, first scanning the empty ward as if about to disclose a momentous secret. "I don't need to eat, not now. I can live without it. All I need is sunlight."

"What are you talking about? Do you really think you've turned into a tree? How could a plant talk? How can you think these things?"” (Han \& Smith, 2015, p.153-154),

discloses the grave internal struggle, identity crisis with the existential question. Yeong-hye's vegetarianism totally shrinks her health. Poor nourishment caused muscle atrophy and dystrophy of motor nerves. Remarks like, "her body resembled nothing so much as the skeletal frame of an invalid" (Han \& Smith, 2015, p. 18), "a scrawny thing, just a ghost" (Han \& Smith, 2015, p. 45), "her face was practically bloodless, almost as white as milk" (Han \& Smith, 2015, p. 46), describes her body in an unhealthy light. But the etiological question remains. To quote, "An illness, like 
anything else, is properly defined by specifying its essence - that which is present in all instances of it and unique to it" (Steurer et al., 2006, p. 87). The book The Vegetarian, however, configures multiple indicative answers to the illness, and a singular signification is delayed.

Despite Yeong-hye's deteriorating body and mind, she is shown in the light of sexual mania when the narrator is the unnamed brother-in-law of Yeong-hye, the husband of In-hye. He is curious about the hospital episodes of Yeong-hye's "bizarre" behaviors, and obsessed with the mongoloid mark on her buttock, which he accidently saw when she was out of bath. He anticipates a sexuality which will meet his personal fetish for the plant kingdom. He uses a studio apartment to shoot a video of Yeong-hye's bare body. The aesthetics of this painter artist, who paints flowers all over Yeong-hye, soon exposes as a sexual fetish of a latent pornographer. He takes advantage of the corporeal and clinical condition of Yeong-hye and convinces her to offer her asexual vegetarian body as a sex object. He choreographs a sex scene between two bodies (of his friend and Yeong-hye, painted green) and eventually ends up raping Yeong-hye. The carnal monstrosity of his character develops into an insatiable greed of a consumer, another cause of the rejection of consumption by Yeong-hye. His description of her body mark:

"Its pale blue-green resembled that of a faint bruise, but it was clearly a Mongolian mark. It called to mind something ancient, something pre-evolutionary, or else perhaps a mark of photosynthesis, and he realized to his surprise that there was nothing at all sexual about it; it was more vegetal than sexual" (Han \& Smith, 2015, p. 83),

is a clear telling of how he scanned, scrutinized, compared the impact of a mark with the vegetal world while romanticizing the entire disease of Yeong-hye. The "mad" woman, the "abnormal" women's abnormality, is a darkness which is colonized by the men of the same society Yeong-hye lives in, with an intention of civilizing the "primitive" nature of woman. There is a power play, a relation of docility and utility, which Michel Foucault calls a mode of disciplining.

\section{Clinical Condition, Dream Sequence and its Impact on the Nature of Illness}

"A body is docile that may be subjected, used, transformed and improved" (Foucault \& Sheridan, 1995, p. 136).

The discourse of Yeong-hye's body largely dwells on the very aspect of her expected utility as a sex object and her discord and disobedience regarding such disciplining, which complicates her mind. The docility subjected on her body is overturned by her resistance, and meat becomes a symbol of the cultural paranoia she is struggling to oppose. Her disease is a mix of many causes and consequent effects, fitted into jargons of medical terms. The hospitals Yeong-hye was admitted to labeled her condition as anorexia nervosa, schizophrenia and paranoia, and perhaps she had them all, but there is a total ignorance of the oppressive gender power-play in the household, unhealthy sexual encounters and PTSD of childhood meat repulsions, which are grave causes of her trauma. Throughout the text the medical institutions were unable to find a cure, and ended up explaining her situation of survival in phrases like "if we're lucky" (Han \& Smith, 2015, p. 140), "will starve to death" (Han \& Smith, 2015, p.140), "we're still not sure" (Han \& Smith, 2015, p. 141), "can't be sure of keeping her alive" (Han \& Smith, 2015,p. 141). Yeong-hye's body is dominated with an IV needle, tranquiller, nose feeding tube and other "remedies", only making her condition worse. These straight-jacketed means of disciple and punish says how, "the human body is itself a politically inscribed entity, its physiology and morphology shaped by histories and practices of containment and control" (Bordo, 1993, p.21). In this case, the cultural politics of condemning bodies on the basis of gender ideology is evidentiary. Medical institutions record the 
pathological problem based on the current symptoms, but fail to cure because the enigma of the disease is rooted in moments of subjugation caused by human relationships.

The nature of Yeong-hye's illness dismantles the mind/body, nature/culture, reality/dream polarity. The episode where she escapes from the walled room of her mental institution and bares herself on a bench, with a half-eaten dead bird clenched in her hand, discloses her exhaustion from the control of the masculine world and her consequential lack of control over her own world. Her next escape from Ch'ukseong Psychiatric Hospital is to the Ch'ukseong mountain, when she soaked herself in rain and was found rooted to the ground, looking upward at the sky like an abstracted plant. On being brought back to the hospital ward, Yeong-hye performed a hand-stand and engaged herself in the illusion of her body sprouting plant-parts. She suffered from protracted insomnia, menstrual disturbances, and squatted down towards sunlight, considering it as her only source of food.

It is here that the dreams of Yeong-hye come into play, an aspect which is medically ignored in the anomaly of her disease. In this text, the world of Yeong-hye's dream is packed with grotesque images and aesthetics of blood. There is a noteworthy recurrence of the dreams of faces, along with the pageant of dreams of murder, palimpsest of horrific thoughts, feeling of suffocation and imprisonment in a dark world, fingers flexing to kill, leaky butcher shops, throttling hands, trembling legs, animal lives wiggling in Yeong-hye's stomach. There is a spectacle of the process, frequency and pace of chewing meat, descriptions of body parts involved in such a process, the motif of melting bodies, especially faces. The readers plunge in a darker world with the horrors of the human body and the elaborate imagery of excess and body fluids. Also, the motif gazing eyes of dead animals, sounds like yells and howls, the oppression of a weight on the chest in the form of an imagined lump, anxious temperature changes dominate the subconscious mind. In the dreams, we are also exposed to the character In-hye, whose suffering equates that of Yeong-hye. The narrative soon indicates at the issue of family medical history and that Yeong-hye is not the sole suffering woman in the plot. Susan Bordo rightly comments, "we are all exposed to, rather, are homogenizing and normalizing images and ideologies concerning "femininity" and female beauty...The unique configurations (of ethnicity, social class, sexual orientation, religion, genetics, education, family, age, and so forth) that make up each person's life will determine how each actual woman is affected by our culture" (Bordo, 1993, p. 62). The diverse patterns of coercion lead to diverse consequences. In the case of Yeong-hye, she has her own permutations and combinations of trauma which is unique to her, but heterogeneous enough to evade an origin point of her disease.

There is a visible failure in the method of forceful feeding of food and tablets. The lack of outcome from the medical care generated the following response:

“'Today we"ll try feeding her some gruel intravenously, and if we're lucky her condition might improve a little. Otherwise there'll be nothing else for it but transfer her to one of the critical wards at a general hospital"' (Han \& Smith, 2015, p. 140).

This is crucial because the doctors gave up on the technique of persuasion in the case of Yeonghye, until her sister took the responsibility of curing her by comprehending the latent and subtle social barriers and conditionings the former was trying to break which are invisible to the unobservant.

\section{Conclusion}

When we talk about the difficulty of disease taxonomy in Han Kang's text, we understand that a nomenclature which is achieved after the organization and categorization of a well defined illness 
is confounding here. Yeong-hye's condition questions all objective facts and eludes etiology, a word which is locatable in Robert Koch's postulates, the cause-effect relations between a bacteria and a disease. Such direct absolutes are implausible in the context of the text and difficult in psychiatry. The fantastic elements, magic realism and stream of consciousness in the text heighten the aspect of subconscious and unconscious mind and there is an acute struggle in a scientific and clinical evaluation of the illness condition. When we consider the social etiology model, which singles out one specific disorder (operational or discreet) for investigation, Yeonghye's case in non-applicable. In contrast to these models is the social consequences model. To quote,

"key element of the social consequences model is the idea that mental and emotional disorder is a normal byproduct of society (Aneshensel 1992; Aneshensel and Phelan 1999; Pearlin 1989). In other words, the very structures and processes that make social life possible for most people create circumstances that are intolerable for some person" ((Aneshensel, 2005, p 224).

Also,

"This orientation distinctly differs from the disease model of medicine in which disorder is viewed as abnormal, the outcome of some dysfunction in social or other etiological factors. This pathological orientation leads inevitably to the individualization of risk. In contrast, the social consequences model examines regularities in social organization and processes that place populations, as distinct from individuals, at elevated risk. This means that sociological research tends to look for the sources of mental disorder in the usual, not the esoteric (Pearlin 1989)" (Aneshensel, 2005, p. 224).

Diverse variables come into play and construct the disorder of Yeong-hye and her sister In-hye. These variables are "on-going" and non-specific. Nevertheless, these variables are found in the usual day to day life, but they are neglected under the domination of cultural rules and unsaid power plays. Han Kang's novel The Vegetarian deconstructs a single-disorder approach towards comprehending the "whatness" of a disease, and hence a struggle in taxonomy persists.

\section{References}

Bordo, S. (1993). Unbearable weight: feminism, Western culture, and the body. University of California Press.

Kim, W.C. (2019). Eating and Suffering in Han Kang's The Vegetarian. CLCWeb: Comparative Literature and Culture, 21(5), 2-10. https://doi.org/10.7771/1481-4374.3390

Han, K., \& Smith, D. (2015). The Vegetarian: A novel. Portobello Books.

Aneshensel, C. S. (2005). Research in Mental Health: Social Etiology versus Social Consequences. Journal of Health and Social Behavior, 46(3), 221-228. https://doi.org/10.1177/002214650504600301

Steurer, J., Bachmann, L. M., \& Miettinen, O. S. (2006). Etiology in a Taxonomy of Illnesses. European Journal of Epidemiology, 21(2), 85-89. https://doi.org/10.1007/s10654-005-5925-4

Foucault, M. (2003). The Birth of the clinic: An archeology of medical perception. (A. Sheridan, Trans.). Routledge.

Foucault, M. (1995). Discipline and punish: the birth of the prison. (A. Sheridan, Trans.). Vintage Books.

Jharna Choudhury is a Ph.D. Scholar, from the Department of English, Tezpur University, Assam, India. She is currently working on her thesis: 'Spectres of the Corporeal: The Grotesque Body in Contemporary Fiction'. 